\title{
A Cost-Effectiveness Analysis of Screening Strategies involving Noninvasive Prenatal Testing for Trisomy 21
}

\section{Shuxian Wang}

Peking University First Hospital https://orcid.org/0000-0002-2042-3962

Kejun Liu

China National Health Development Research Center

Huixia Yang

Peking University First Hospital

Jingmei Ma ( $\nabla$ jingmeima@bjmu.edu.cn )

Research article

Keywords: Noninvasive prenatal testing (NIPT), Cell-free DNA (cf-DNA), Traditional triple serum screening, Cost-effectiveness analysis, Trisomy 21 (T21)

Posted Date: January 14th, 2020

DOl: https://doi.org/10.21203/rs.2.20761/v1

License: @ (i) This work is licensed under a Creative Commons Attribution 4.0 International License. Read Full License 


\section{Abstract}

In the trends of increasing advanced maternal age (AMA) and decreasing cost of Noninvasive Prenatal Testing (NIPT), we investigated the benefits and cost effectiveness of NIPT as primary or contingent strategies for trisomy 21 (T21). A theoretical model involving 1,000,000 single pregnancies was established. We presented five screening scenarios, primary NIPT (Strategy 1), contingent NIPT after traditional triple serum screening higher than $1 / 300$ or 1/1000 (Strategy 2-1 or Strategy 2-2) and agebased (Strategy 3). Strategy 3 was stratified, in which 1) for advanced maternal age (AMA) of 40 and more, prenatal diagnosis was offered, 2) for AMA of 35 to 39 , NIPT was introduced, 3 ) if younger than 35, contingent strategy with screening risk higher than 1:300 (Strategy 3-1) or 1:1000 (Strategy 3-2) will be offered NIPT. Parameters were referred to publications or on-site verification. The primary outcome was incremental cost analysis for each strategy on baseline and alterative assumptions, which take aging society, reducing cost of NIPT and compliance into consideration. The second outcomes were total cost, cost-effect and cost-benefit analysis. If the incremental cost was less than 0.215 million US\$, which was cost for raising one T21 child, or the benefit-to-cost ratio over 1, then the strategy was defined as "costeffective". The anticipated prenatal diagnosis was significantly reduced in Strategy 1 and 2, most notably in Strategy 2-1. For the incremental costs, strategy 2-1 was set as baseline. All other strategy costed more than raising one T21 except 3-1. In sensitivity analysis, strategy 1 costed the least when NIPT was lower than 47 US\$. If NIPT less than 131 US\$, the incremental cost of any strategy was less than 0.215 million US\$. When the proportion of AMA accounted for more than $15 \%$ and $20 \%$ of population, incremental costs of strategy 3-1 and 3-2 were cost effective. In conclusion, contingent NIPT after traditional triple serum screening (risk higher than 1/300) was optimal in total cost (130 million US\$), cost-effect (33.4 thousand US\$) and cost-benefit (ratio=4.90) analysis of the model. Age-based strategy was optimal as AMA proportion and NIPT acceptance increased. The primary NIPT was most effective for certain price.

\section{Background}

Trisomy 21 (T21) is the most frequent aneuploidy occurred at birth ${ }^{1}$. It is associated with developmental and neurocognitive delay ${ }^{2}$. T21 related testing in routine prenatal care is available worldwide ${ }^{3,4}$. To avoid the invasive procedure-related miscarriage, diagnostic testing through chorionic villus sampling (CVS), amniocentesis and cordocentesis is confined to certain high-risk population ${ }^{5}$. Traditional triple serum screening (AFP, $\beta$-hCG and uE3) in mid-trimester is most frequently adopted in China ${ }^{6}$, accounting for $40 \%$ of the registration. As an important supplementary for those missing the window period for NT measurements in the first trimester antenatal care, the detection rate (DR) varies between $60 \%-93 \%$ if fixing false positive rate (FPR) of $3 \%$.

Since 2011, noninvasive prenatal testing (NIPT), based on cell-free DNA derived from placental trophoblast cells into maternal circulation, has been applied to clinical practice as new screening method $^{8-10}$. Overall, the clinical validation for T21 presented to be optimal with high DR $(96-100 \%)$ and low FPR $(0-0.2 \%)^{11-13}$. The implementation of NIPT reduced unnecessary prenatal diagnosis and 
concomitant procedure related fetal loss, although prenatal diagnosis could detect many other genetic abnormalities ${ }^{14}$. From the perspective of public health, controversies on how to introduce NIPT into clinics have yet to be solved till now.

International society for prenatal diagnosis (ISPD) ${ }^{7}$ and American College of Medical Genetics and Genomics (ACMG) ${ }^{15}$ suggested that NIPT could be used as first-tier screening test in general population. One Chinese study involving 31515 pregnancies further supports NIPT as primary strategy in terms of its accurate and reliable capacity ${ }^{16}$. International Society of Ultrasound in Obstetrics and Gynecology (ISUOG) ${ }^{17}$ recommended the contingent NIPT strategy until NIPT costs decreased. ISPD also suggested that contingent NIPT can be applied based on local situation. In 2016, Chinese recommendation ${ }^{18}$ affirmed the contingent NIPT strategy, in which NIPT is suitable for pregnancies with intermediate risk (1/1000). In 2018, Chinese guideline for preconception care and prenatal care ${ }^{19}$ put forward the contingent NIPT strategy with age-stratification. It suggested that primary NIPT could be offered to pregnancies with maternal age of $35 \sim 39$, and the direct prenatal diagnosis should be offered to those with age 40 and more. Given the trends of delayed reproductive age and falling in NIPT cost, current strategy is in controversary and varies in application.

Cost-effectiveness analysis is essential for the evaluation of different strategies in the perspective of public health. Comparing with primary NIPT, the implementation among "high risk" populations is more cost-effective ${ }^{20-24}$. Considering the high positive predictive value (PPV) among AMA, there are some evidences on advantage of strategy with age stratification. One study preformed in Turkey sub-grouping pregnancies into AMA (35 year) and others, and found that in either group, the primary NIPT was less costly ${ }^{25}$. Setting "primary NIPT" as baseline, Evans' study ${ }^{24}$ from US compared age-based strategy with contingent NIPT among general populations. They concluded that the contingent NIPT with risk cut-off as $1 / 1000$, other than $1 / 300$ was cost-effective in cost-effect and incremental cost analysis. Ayres AC et.al. ${ }^{23}$ confirmed that age-based strategy (defined AMA as 40 or 35) was dominant in incremental cost when setting "combined first trimester screening" as baseline. In general, the pre-classification based on maternal age should be considered, especially in an aging society. For instance, with the "second child policy" applied in China, the AMA population has been increasing ${ }^{26}$.

In the context of rapid public health coverage of NIPT, the application became heterogeneous from countries to regions. The most efficient and affordable way for NIPT implementation needs to be explored $^{27}$. We adopted NIPT primary, contingent and age-based strategies in one theoretical model for cost effective analysis. The risk cut-off was set as 1/300 and 1/1000 in the contingent strategy. In agebased strategy, AMA was subdivided into over 40 or between $35-39$. The costly performance was further verified with sensitivity analysis, in accordance with trends of increasing advanced maternal age (AMA) and decreasing cost of NIPT.

\section{Methods}




\section{Simulation model}

This study was exempted from ethics committee approval for the pure theoretical model involving $1,000,000$ single pregnancies in China.

We presented five screening scenarios (Fig. 1). Primary NIPT (Strategy 1), contingent NIPT after traditional triple serum screening higher than $1 / 300$ or $1 / 1000$ (Strategy $2-1$ or Strategy $2-2$ ) and agebased (Strategy 3). Strategy 3 was stratified based on maternal age, in which 1) AMA of 40 and more, prenatal diagnosis was offered, 2) for AMA of 35 to 39, NIPT was introduced, 3) if younger than 35, contingent strategy with risk higher than 1:300 (Strategy $3-1$ ) or 1:1000 (Strategy $3-2$ ) will be offered.

The primary outcome was incremental cost analysis for each strategy on baseline and alterative assumptions, which took following factors into consideration, aging society, reducing cost of NIPT and compliance. The second outcomes were the comparisons among five strategies on total cost, cost-effect and cost-benefit analysis ${ }^{28}$.

\section{Model parameters}

The related parameters were set after thorough review of related publications or on-site verification. The proportion of pregnancies younger than 35 , aged for $35-39$ and over 40 accounted for $85 \%, 13 \%$ and $2 \%$ respectively ${ }^{24,29}$. The total livebirth incidence of T21 was $1 / 565^{24}$. The rate of each age subgroup was recalculated ${ }^{29,30}$. The $T 21$ incidence in the second trimester was determined by dividing the liveborn incidence rate by $0.76^{24,31}$. The sensitivity (Sen) of traditional triple screening was set following the SURUSS study ${ }^{32}$, characterized by $83 \%$ in high risk population with $1 / 300$ and $95 \%$ with $1 / 1000$. The Sen and FPR of NIPT was $99.3 \%$ and $0.2 \%$, which was moderate based on previous studies ${ }^{33-35}$. The procedure related miscarriage was $0.35 \%{ }^{36}$.

Cost parameters varied based on local administrative department. Counseling costs varied between 8 and 42 US\$, and 14 US\$ on average was adopted. Prices for traditional screening varied between 28 and 71 US\$, and 35 US\$ was adopted for triple serum screening. NIPT price was 325 US\$. Costs for prenatal diagnosis varied between 127 and 247 US\$, and 212 US\$ was adopted for amniocentesis and karyotype analysis. The cost associated with miscarriage or pregnancy termination varied between 353 and 636 US\$ and was estimated to be 424 US\$ on average.

Cost for missed cases was determined by integrating published articles ${ }^{37,38}$, nationwide and regional parameters, such as consumer price index (CPI) and gross domestic products (GDP). The cost was set as 0.215 million US\$. It mainly consisted of direct and indirect economic burdens. The former included medical cost (such as costs for surgery, inpatient and recovery), related medical cost (such as transportation fees) and developmental service support (such as specific education). The latter mainly referred to the economic damage caused by patients due to labor loss, and by parents for accompany.

\section{The parameter calculation}


The total costs were calculated from social prospective ${ }^{39}$. It included medical costs (prenatal clinical and laboratory costs) and postnatal costs for missed cases.

Cost-effectiveness analyses were calculated in terms of public health to focus on the "sensitivity" of each strategy. The cost-effect and incremental cost analysis were defined as costs for detecting one T21

livebirth and for one additional T21 livebirth respectively. The cost-benefit analysis was quantified using "benefit-to-cost" ratio. If the incremental cost was less than 0.215 million US\$, which was cost for raising one T21 child, or the benefit-to-cost ratio over 1, then the strategy was defined as "cost-effective".

For safety analysis, it was defined as the number of patients undergoing prenatal diagnosis for detecting one T21.

\section{Assumptions}

Several assumptions were made to establish a complete model and estimate costs before sensitivity analysis.

1. Following each scenario requirement, all pregnant women accepted NIPT and consecutive prenatal diagnosis if needed.

2. All T21 detected from invasive would be performed termination of pregnancy.

3. The procedure related miscarriages were not calculated as true positive cases.

4. DR and FPR of NIPT were the same in general population regardless of cut-off risks ${ }^{40}$.

\section{Sensitivity analysis}

A sensitivity analysis was performed in which various assumptions in the model was adjusted and to figure out the most important parameters influencing decisions. We mainly focused on incremental cost analysis given that it could reflect "effect" via comparisons among different scenarios, and reflect "benefit" comparing to 0.215 million US\$.

The adjustments were as the following. First, women younger than 35 varied between $70 \%-90 \%$ under the premise of women over 40 unchanged, which was in accordance with age proportion characteristics nowadays. Second, NIPT price varied between 0 and 325 US\$. Third, 30-90\% pregnant women with high risk after serum screening would accept NIPT ${ }^{6,41}$. Fourth, $90 \%$ pregnant women with positive screening results would accept prenatal diagnosis, based on national guidelines and rate observed ${ }^{18}$ (Table 1). 
Table 1

Base and alternative values used in this study

\begin{tabular}{|lll}
\hline Variable & Baseline & Alternative parameters \\
\hline$<35$ & $85 \%$ & $70-90 \%^{*}$ \\
\hline $35 y-39$ & $13 \%$ & $28 \%-8 \%^{*}$ \\
\hline$\geqq 40$ & $2 \%$ & $2 \%$ \\
\hline NIPT (US\$) & 325 & $0-325^{\#}$ \\
\hline Accepted NIPT test & $100 \%$ & $30-100 \%^{*}$ \\
\hline
\end{tabular}

Accepted invasive test $100 \% \quad 90-100 \%$ *

* Interval analysis: The alternative parameters were analyzed at specific points with $5 \%$ or $10 \%$ interval.

\# Continuous analysis: The alternative NIPT cost was analyzed at each point continuously.

\section{Results}

\section{Baseline analysis}

The performance of each strategy was shown in Table 2. The number of true positive cases were similar among three strategies. NIPT primary strategy 1 detected 2315 true T21 with 12 missed cases. Followed by strategy $3-2$ (2276). Overall, strategy $2-1$ detected the least with 312 missed cases. 
Table 2

The performance and accuracy of different strategies.

\begin{tabular}{|llllll|}
\hline Parameter & Strategy & Strategy 2 & Strategy & Strategy 3 & Strategy 3 \\
& 1 & -1 & $2-2$ & -1 & -2 \\
\hline Sensitivity & $99.3 \%$ & $83 \%$ & $95 \%$ & - & \\
\hline False Positive Rate & $0.2 \%$ & $8 \%$ & $26 \%$ & - & \\
\hline High-risk population & & & & & \\
\hline $\begin{array}{l}\text { True Positive Cases (T21 } \\
\text { incidence) }\end{array}$ & - & 81749 & 261608 & 68817 & 221752 \\
\hline Total (1/429) & & & & & \\
\hline$<35(1 / 780)$ & 2315 & 1921 & 2199 & 2146 & 2276 \\
\hline $35-39(1 / 201)$ & - & - & - & 898 & 1028 \\
\hline$\geqq 40(1 / 33)$ & - & - & - & 642 & 642 \\
\hline Missed cases of T21 & - & - & - & 606 & 606 \\
\hline Prenatal Diagnosis & 12 & 312 & 100 & 150 & 50 \\
\hline Total & & & & & 20000 \\
\hline$<35$ & 4310 & 2081 & 2718 & 21935 & 22370 \\
\hline $35-39$ & - & - & - & 1034 & 1469 \\
\hline$\geqq 40$ & - & - & - & 901 & 901 \\
\hline Safety analysis & 1.9 & 1.1 & 1.2 & 10.2 & 9.8 \\
\hline
\end{tabular}

The main differences were the anticipated number of invasive tests, which was significantly reduced with NIPT implementation. For example, there were 4310 cases performing prenatal diagnosis in strategy 1 . The most anticipated invasive number was in strategy $3-2$ (22370). Compared to this, it was reduced by 17,625 and 18,060 in strategy 1 , and further reduced by 2,229 and 1,592 in strategy $2-1$ and $2-2$.

In safety analysis, the indicator was appropriate 1 in contingent strategy $2-1$ and 2-2, lower than NIPT primary strategy 1 with 1.9 and age-based strategy $3-1$ and $3-2$ with around 10 . Hence, the safer of the strategy, the less iatrogenic miscarriages existed.

\section{Cost analysis}

Considering total cost to the society, strategy 1 needed most (330 million US\$), in which medical costs accounted for appropriately $99 \%$ and the remaining $1 \%$ were for missed viable cases. Total costs were 
least with 130 or 148 million US\$ in the strategy $2-1$ and $2-2$. Comparing to $2-2$, the $2-1$ saved 62 and 18 million US\$ in medical costs and total costs respectively. Cost-effect analysis also demonstrated that strategy 1 costed most with 141 thousand US\$ while strategy $2-1$ only needed 33.4 thousand US\$ (Fig. 2).

In cost-benefit analysis, the benefit-to-cost ratio in strategy 1 was least as 1.16 . The highest cost-benefit ratio of 4.90 and 2.85 were presented in Strategy $2-1$ and 2-2, while strategy 3 presented a moderate level of 3.44 and 2.37 .

As strategy $2-1$ avoided the most invasive tests with the best performance in total cost, cost-effect and cost-benefit analysis, it was set as the baseline for incremental costs and further comparations. For T21 detection, strategy 1 needed the most incremental costs ( 0.67 million US\$), followed by strategy $3-2$ (0.25 million US\$) and strategy 2-2 (0.22 million US\$), which were all less superior than strategy $2-1$. While strategy $3-1$ needed 0.165 million US\$, with best performance for the primary outcome (Table 3). 
Table 3

The incremental cost analysis of corresponding strategies on baseline and alternative assumptions compared with strategy $2-1$.

\begin{tabular}{|c|c|c|c|c|c|}
\hline $\begin{array}{l}\text { Sensitivity analysis } \\
\text { (Million US\$) }\end{array}$ & $\begin{array}{l}\text { Strategy } \\
1\end{array}$ & $\begin{array}{l}\text { Strategy } \\
2-1\end{array}$ & $\begin{array}{l}\text { Strategy } \\
2-2\end{array}$ & $\begin{array}{l}\text { Strategy } 3 \\
-1\end{array}$ & $\begin{array}{l}\text { Strategy } 3 \\
-2\end{array}$ \\
\hline Baseline & $0.67: 1$ & - & $0.223: 1$ & $0.165: 1^{*}$ & $0.25: 1$ \\
\hline \multicolumn{6}{|c|}{$\begin{array}{l}\text { Age composition ratio range (< } \\
35 / 35-39)\end{array}$} \\
\hline $70 / 28 \%$ & \multirow[t]{5}{*}{0.67} & - & \multirow[t]{5}{*}{0.223} & $0.09 *$ & 0.13 \\
\hline $75 / 23 \%$ & & - & & $0.1^{*}$ & 0.15 \\
\hline $80 / 18 \%$ & & - & & $0.12^{*}$ & 0.18 \\
\hline $85 / 13 \%$ & & - & & $0.165^{\star}$ & 0.25 \\
\hline $90 / 8 \%$ & & $--\star$ & & 0.76 & 0.47 \\
\hline \multicolumn{6}{|l|}{ NIPT acceptance range } \\
\hline $30 \%$ & $0.67: 1$ & - & $0.169: 1^{\star}$ & $-0.08: 1$ & $-0.39: 1$ \\
\hline $40 \%$ & $0.67: 1$ & - & $0.175: 1^{\star}$ & $-0.11: 1$ & $-0.74: 1$ \\
\hline $50 \%$ & $0.67: 1$ & - & $0.18: 1^{\star}$ & $-0.165: 1$ & $-3.52: 1$ \\
\hline $60 \%$ & $0.67: 1$ & - & $0.19: 1^{\star}$ & $-0.31: 1$ & $1.45: 1$ \\
\hline $70 \%$ & $0.66: 1$ & - & $0.199: 1^{*}$ & $-1.58: 1$ & $0.63: 1$ \\
\hline $80 \%$ & $0.66: 1$ & - & $0.206: 1^{*}$ & $0.57: 1$ & $0.41: 1$ \\
\hline $90 \%$ & $0.66: 1$ & - & $0.21: 1^{*}$ & $0.25: 1$ & $0.31: 1$ \\
\hline PD acceptance with $90 \%$ & $0.67: 1$ & - & $0.22: 1$ & $0.165: 1^{*}$ & $0.25: 1$ \\
\hline
\end{tabular}

Note: * The "appropriate" scenario in which incremental costs are least or lower than costs for raising one viable T21 (0.215 million US\$).

\section{Sensitivity analysis}

In general, strategy 1 remained as the most incremental costs regardless of age proportion (Table 3 ). If the age proportion for women over 40 , between $35-39$ and younger than 35 accounted for $2 \%, 8 \%$ and $90 \%$, incremental costs of all other scenarios were more than 0.215 million US\$, and strategy $2-1$ was most cost-effective. When the proportion of pregnancies older than 35 increased and reached to $15 \%$, strategy $3-1$ needed 0.165 million US\$, while others still needed more than 0.215 million US\$. If the older proportion was further decreased, such as $20 \%$, the incremental costs of strategy $3-1$ and $3-2$ were 
decreased to 0.12 and 0.18 million US\$. The pattern showed the advantages of age-based strategy as the AMA increased.

As shown in Fig. 3, When NIPT price was lower than 317, 278 or 131 US\$ respectively, strategy 2-2, 3 - 2 and 1 were superior to $2-1$ and considered as "appropriate". Strategy $3-1$ was most cost-effective with NIPT price higher than 47 US\$. If NIPT price was lower than 47 or 39 US\$, primary NIPT strategy detected most cases with least incremental cost or at a saving cost, and could be recommended as optimal.

If the rates for accepting NIPT varied between $30 \%$ and $90 \%$, the incremental costs ranged between 0.169 and 0.21 million US\$, making strategy $2-2$ the most cost-effective strategy. If $100 \%$ pregnancies would accept NIPT, the incremental cost of strategy 2-2 was 0.22 million US\$, which was higher than raising one viable T21 (Table 3).

If rates for accepting prenatal diagnosis was adjusted to $90 \%$, the incremental costs of each strategy increased little without any impact on determination (Table 3).

\section{Discussion}

In our study, we found that NIPT primary to general population could fulfill efficient screening for T21 but more costly. Contingent NIPT with risk threshold as 1/300 (strategy $2-1$ ) could effectively reduce unnecessary invasive testing, with best performance in total cost, cost effect and benefit analysis. Setting strategy 2-1 as the baseline, current Chinese age-stratified contingent NIPT (strategy $3-1$ ) detected one additional case with least incremental cost, which was also less than the costs needed to raise one viable T21. Taking the aging society for sensitivity analysis, strategy $3-1$ was optimal with increasing proportion of AMA, and vice versa. The primary NIPT demonstrated its screening accuracy among all the scenarios as the most cost effectiveness option when the price dropped to 47 US\$.

Overall, our study proposed the advantages of contingent NIPT in "high risk" population in total costs and cost-effect analysis, which was consistent with previous studies ${ }^{21-24}$. Prenatal diagnosis has been directly provided to AMA. T21 incidence in AMA was similar to those identified by serum screening among general populations ${ }^{40,42}$, which provide rational evidences to provide direct invasive tests for AMA, and therefore we specifically considered the influence of aging society in sensitivity analysis. The advantage of age-based strategy was more prominent when AMA increased. The reverse was also true. Strategy $3-1$ remained to be the best option if the reproductive age delayed, with pregnancies younger than 35 less than $85 \%$.

In current study, the appropriate threshold for contingent strategy was different from Evans et al study ${ }^{24}$ although both studies shared similar design on age proportion and NIPT acceptance in total cost and cost effect analysis. In fact, both studies found that contingent strategy with 1/300 was optimal without taking costs for raising T21 into consideration. In incremental cost analysis, the underlying explanation could relate to the NIPT price, which was relative higher in our system, along with the increased cases adopting NIPT when lower the cut-off to 1/1000. When NIPT acceptance changed, the incremental cost 
tendency was opposite in age-stratified and contingent strategy. The inconsistence also verified the key influence of NIPT price on decision of strategy implementation, that is the advantages of age-based strategy was dominant if NIPT price increased.

When sequencing is affordable, primary NIPT has been launched as the optimal choice with wide application in some countries and regions ${ }^{27}$. In sensitive analysis of our model, the tendency of incremental cost changed the most in primary NIPT. With decreasing NIPT cost ${ }^{43}$, primary NIPT becomes costly and dominant. Meanwhile, in other scenarios, the incremental costs changed less due to the costs for testing or miscarriage were far below to make the influence.

Current study provide evidence from public health perspective on how to introduce NIPT into clinics. Using parameters of real world, the proposed strategy verified the current guideline. We raised two key factors influencing the policy making, which should be taken into consideration periodically in the context of aging and NIPT price reduction. There were several strengthens. The widely used clinical indications for NIPT were AMA and high risk identified by serum screening ${ }^{44}$, hence both contingent and agestratified strategies were involved in design. Taking $1 / 300$ and 1/1000 into consideration enabled us to identify the more appropriate risk level for NIPT. For areas with different NIPT prices, the sensitive analysis of tendency for incremental costs enable us to cover real-world situations in different regions to figure out the turning point.

There were several limitations for the theoretical model. First, this is a theoretical model. Although the associated publications had been integrated to determine the parameters, with further analysis through sensitivity analysis, the conclusion could be augured on the actual costs, the demographics of the population, the degree of utilization, or all other real-life factors. Second, the value of primary NIPT should extend to other genetic anomalies including the copy number variations ${ }^{14,45}$. At present, NIPT cannot replace the prenatal diagnosis (CVS or amniocentesis) given the accuracy and wide detectable spectrum with the development of next generation sequencing (NGS) ${ }^{46}$. The importance of prenatal diagnosis has been emphasized by professional guidelines worldwide, and offered as an option for general pregnancies. T21 detection was the priority in this model. The consideration was that the primary indication of prenatal diagnosis has been the advanced maternal age (AMA) in the context of delayed reproductive age. Third, the model didn't take religious and cultural factors into consideration. Fourth, due to absence of social investigation, the study focused on public health perspective other than views from all stakeholder. Last, we didn't calculate quality adjusted life years (QALY), which is standard and desirable indicator in cost-utility analysis ${ }^{47}$. The controversial and area-specific judgement of parental preferences in prenatal diagnosis ${ }^{48}$ was the main concern. Some possible collateral effects such as work absence was negligible and we didn't include it in our analysis.

\section{Conclusions}

NIPT has higher accuracy for prenatal assessment of fetal anomaly especially for T21, which represents the advanced technology in prenatal screening ${ }^{49}$. According to cost-effectiveness analysis, NIPT was 
more appropriate among high risk population, either with positive serum screening or AMA. Briefly, contingent strategy with 1:300 (Strategy $2-1$ ) was most cost-effective in total cost, cost effect and costbenefit analysis. Age-based strategy was optimal in incremental cost analysis, and became more appropriate as AMA or NIPT acceptance increased. The clinical benefits of primary NIPT became more meaningful on the premise of achieving cost savings at an appropriate unit cost ${ }^{50,51}$.

\section{Declarations}

\section{Patient and Public Involvement}

No patients and public have involved the research for the pure theoretical model.

\section{Dissemination declaration}

We are expected to publish one or more scientific manuscripts on peer-reviewed journals. We also plan to present our results on national and international conferences through oral or postal presentations for further dissemination.

\section{Authors' contributions}

SX.W., KJ. L, HX.Y. and JM.M. conceived the study design. SX.W. drafted the manuscript. KJ. L helped in cost-effectiveness analysis. HX.Y. and JM.M. helped in developing main clinical strategies and revising the manuscript. All authors provided critical input to the manuscript. The Corresponding Authors has the right to grant on behalf of all authors and does grant on behalf of all authors

\section{Competing interests}

The authors have no conflict of interests

\section{Acknowledgements}

We are grateful for the supporting of National Key Technologies R\&D program of China (2016YFC1000303).

\section{Funding}

National Key Technologies R\&D program of China (2016YFC1000303).

\section{Availability of data and materials}

All the data will be available from on-site verification or published articles

\section{Consent for publication}


The participated parents have made an informed consent to participate in the study for research purposes.

\section{References}

1. Plaiasu V: Down Syndrome - Genetics and Cardiogenetics. Maedica (Buchar) 2017, 12(3):208-213.

2. Levenson D: Talking about Down syndrome. Am J Med Genet A 2009, 149a(4):vii-viii.

3. Malone FD, Canick JA, Ball RH, Nyberg DA, Comstock CH, Bukowski R, Berkowitz RL, Gross SJ,Dugoff L, Craigo SD et al: First-trimester or second-trimester screening, or both, for Down's syndrome. N Engl J Med 2005, 353(19):2001-2011.

4. Lam YH, Lee CP, Sin SY, Tang R, Wong HS, Wong SF, Fong DY, Tang MH, Woo HH: Comparison and integration of first trimester fetal nuchal translucency and second trimester maternal serum screening for fetal Down syndrome. Prenat Diagn 2002, 22(8):730-735.

5. Jaques AM, Collins VR, Muggli EE, Amor DJ, Francis I, Sheffield LJ, Halliday JL: Uptake of prenatal diagnostic testing and the effectiveness of prenatal screening for Down syndrome. Prenat Diagn 2010, 30(6):522-530.

6. Tu S, Rosenthal M, Wang D, Huang J, Chen Y: Performance of prenatal screening using maternal serum and ultrasound markers for Down syndrome in Chinese women: a systematic review and meta-analysis. Bjog 2016, 123 Suppl 3:12-22.

7. Benn P, Borrell A, Chiu RW, Cuckle H, Dugoff L, Faas B, Gross S, Huang T, Johnson J, Maymon R et al: Position statement from the Chromosome Abnormality Screening Committee on behalf of the Board of the International Society for Prenatal Diagnosis. Prenat Diagn 2015, 35(8):725-734.

8. Palomaki GE, Kloza EM, Lambert-Messerlian GM, Haddow JE, Neveux LM, Ehrich M, van den Boom D, Bombard AT, Deciu C, Grody WW et al: DNA sequencing of maternal plasma to detect Down syndrome: an international clinical validation study. Genet Med 2011, 13(11):913-920.

9. Ehrich M, Deciu C, Zwiefelhofer T, Tynan JA, Cagasan L, Tim R, Lu V, McCullough R, McCarthy E, Nygren $\mathrm{AO}$ et al: Noninvasive detection of fetal trisomy 21 by sequencing of DNA in maternal blood: a study in a clinical setting. Am J Obstet Gynecol 2011, 204(3):205.e201-211.

10. Allyse MA, Wick MJ: Noninvasive Prenatal Genetic Screening Using Cell-free DNA. Jama 2018, 320(6):591-592.

11. Ma J, Wang Y, Wang W, Dong Y, Xu C, Zhou A, Xu Z, Wu Z, Tang X, Chen F et al: Validation of combinatorial probe-anchor ligation-based sequencing as non-invasive prenatal test for trisomy at a central laboratory. Ultrasound Obstet Gynecol 2017, 50(1):49-57.

12. Bianchi DW, Parker RL, Wentworth J, Madankumar R, Saffer C, Das AF, Craig JA, Chudova DI, Devers $\mathrm{PL}$, Jones $\mathrm{KW}$ et al: DNA sequencing versus standard prenatal aneuploidy screening. $\mathrm{N}$ Engl $\mathrm{J}$ Med 2014, 370(9):799-808.

13. Liang D, Cram DS, Tan H, Linpeng S, Liu Y, Sun H, Zhang Y, Tian F, Zhu H, Xu M et al: Clinical utility of noninvasive prenatal screening for expanded chromosome disease syndromes. Genet Med 2019. 
14. Le Bras A, Salomon LJ, Bussieres L, Malan V, Elie C, Mahallati H, Ville Y, Vekemans M, Durand-Zaleski I: Cost-effectiveness of five screening strategies for trisomies and other unbalanced chromosomal abnormalities: a model-based analysis. Ultrasound Obstet Gynecol 2019.

15. Gregg AR, Skotko BG, Benkendorf JL, Monaghan KG, Bajaj K, Best RG, Klugman S, Watson MS: Noninvasive prenatal screening for fetal aneuploidy, 2016 update: a position statement of the American College of Medical Genetics and Genomics. Genet Med 2016, 18(10):1056-1065.

16. Xu L, Huang $H$, Lin N, Wang $Y$, He D, Zhang M, Chen M, Chen L, Lin Y: Non-invasive cell-free fetal DNA testing: a multicenter follow-up study of 31515 singleton pregnancies in southeastern China. Ultrasound Obstet Gynecol 2019.

17. Salomon LJ, Alfirevic Z, Audibert F, Kagan KO, Paladini D, Yeo G, Raine-Fenning N: ISUOG updated consensus statement on the impact of cfDNA aneuploidy testing on screening policies and prenatal ultrasound practice. Ultrasound Obstet Gynecol 2017, 49(6):815-816.

18. http://www.nhc.gov.cn/fys/s3581/201611/0e6fe5bac1664ebda8bc28ad0ed68389.shtml

19. Preconception care and prenatal care Guideline. Chin J Obstet Gynecol 2018;53;7-13

20. Cuckle H, Benn P, Pergament E: Maternal cfDNA screening for Down syndrome-a cost sensitivity analysis. Prenat Diagn 2013, 33(7):636-642.

21. Song K, Musci TJ, Caughey AB: Clinical utility and cost of non-invasive prenatal testing with cfDNA analysis in high-risk women based on a US population. J Matern Fetal Neonatal Med 2013, 26(12):1180-1185.

22. Colosi E, D'Ambrosio V, Periti E: First trimester contingent screening for trisomies 21,18,13: is this model cost efficient and feasible in public health system? J Matern Fetal Neonatal Med 2017, 30(24):2905-2910.

23. Ayres AC, Whitty JA, Ellwood DA: A cost-effectiveness analysis comparing different strategies to implement noninvasive prenatal testing into a Down syndrome screening program. Aust N Z J Obstet Gynaecol 2014, 54(5):412-417.

24. Evans MI, Sonek JD, Hallahan TW, Krantz DA: Cell-free fetal DNA screening in the USA: a cost analysis of screening strategies. Ultrasound Obstet Gynecol 2015, 45(1):74-83.

25. Okem ZG, Orgul G, Kasnakoglu BT, Cakar M, Beksac MS: Economic analysis of prenatal screening strategies for Down syndrome in singleton pregnancies in Turkey. Eur J Obstet Gynecol Reprod Biol 2017, 219:40-44.

26. Zhang HX, Zhao YY, Wang YQ: Analysis of the Characteristics of Pregnancy and Delivery before and after Implementation of the Two-child Policy. Chin Med J (Engl) 2018, 131(1):37-42.

27. White K, Schmid M, Kostenko E: OP05.10: A global landscape analysis of reimbursement policies for prenatal cell-free DNA testing in public healthcare systems. Ultrasound in Obstetrics \& Gynecology 2019, 54(S1):101-101.

28. Wang $M, M a X$, Tan X. Probe into the application of health economic evaluation methods in prenatal screening scheme for Down Syndrome. China J Fam Plann. 2007; 15: 403-407. 
29. Pan M, Huang LY, Zhen L, Li DZ: A cost-effectiveness analysis comparing two different strategies in advanced maternal age: Combined first-trimester screening and maternal blood cell-free DNA testing. Taiwan J Obstet Gynecol 2018, 57(4):536-540.

30. Cuckle HS, Wald NJ, Thompson SG: Estimating a woman's risk of having a pregnancy associated with Down's syndrome using her age and serum alpha-fetoprotein level. Br J Obstet Gynaecol 1987, 94(5):387-402.

31. Spencer $\mathrm{K}$ : What is the true fetal loss rate in pregnancies affected by trisomy 21 and how does this influence whether first trimester detection rates are superior to those in the second trimester? Prenat Diagn 2001, 21(9):788-789.

32. Wald NJ, Rodeck C, Hackshaw AK, Walters J, Chitty L, Mackinson AM: First and second trimester antenatal screening for Down's syndrome: the results of the Serum, Urine and Ultrasound Screening Study (SURUSS). J Med Screen 2003, 10(2):56-104.

33. Norton ME, Jacobsson B, Swamy GK, Laurent LC, Ranzini AC, Brar H, Tomlinson MW, Pereira L, Spitz $\mathrm{JL}$, Hollemon D et al: Cell-free DNA analysis for noninvasive examination of trisomy. $\mathrm{N}$ Engl J Med 2015, 372(17):1589-1597.

34. Taylor-Phillips S, Freeman K, Geppert J, Agbebiyi A, Uthman OA, Madan J, Clarke A, Quenby S, Clarke A: Accuracy of non-invasive prenatal testing using cell-free DNA for detection of Down, Edwards and Patau syndromes: a systematic review and meta-analysis. BMJ Open 2016, 6(1):e010002.

35. Beta J, Lesmes-Heredia C, Bedetti C, Akolekar R: Risk of miscarriage following amniocentesis and chorionic villus sampling: a systematic review of the literature. Minerva Ginecol 2018, 70(2):215-219.

36. Zhu RF, Li J, Duan HL, Zhang Y, and Xue Y. Health economic evaluation of five prenatal screening strategies for Down's syndrome. Chin J Perinat Med. 2018; 21(9): 632-638.

37. Zhang J, Wang B, Qian X, Shi Q, Chen Y, Li J and Zhu Y. Economic burden of Down Syndrome in China. Chinese Health Economics. 2005;24:51-53. doi:

38. Walker BS, Jackson BR, LaGrave D, Ashwood ER, Schmidt RL: A cost-effectiveness analysis of cell free DNA as a replacement for serum screening for Down syndrome. Prenat Diagn 2015, 35(5):440446.

39. Practice Bulletin No. 163: Screening for Fetal Aneuploidy. Obstet Gynecol 2016, 127(5):e123-137.

40. Ohno M, Caughey A: The role of noninvasive prenatal testing as a diagnostic versus a screening tool-a cost-effectiveness analysis. Prenat Diagn 2013, 33(7):630-635.

41. Wax JR, Chard R, Cartin A, Litton C, Pinette MG, Lucas FL: Noninvasive prenatal testing: the importance of pretest trisomy risk and posttest predictive values. Am J Obstet Gynecol 2015, 212(4):548-549.

42. Beulen L, Grutters JP, Faas BH, Feenstra I, van Vugt JM, Bekker MN: The consequences of implementing non-invasive prenatal testing in Dutch national health care: a cost-effectiveness analysis. Eur J Obstet Gynecol Reprod Biol 2014, 182:53-61.

43. Bellai-Dussault K, Meng L, Huang T, Reszel J, Walker M, Lanes A, Okun N, Armour C, Dougan S: A two year review of publicly funded cell-free DNA screening in Ontario: utilization and adherence to 
funding criteria. Prenat Diagn 2019.

44. Lefkowitz RB, Tynan JA, Liu T, Wu Y, Mazloom AR, Almasri E, Hogg G, Angkachatchai V, Zhao C, Grosu DS et al: Clinical validation of a noninvasive prenatal test for genomewide detection of fetal copy number variants. Am J Obstet Gynecol 2016, 215(2):227.e221-227.e216.

45. Evans MI, Evans SM, Bennett TA, Wapner RJ: The price of abandoning diagnostic testing for cell-free fetal DNA screening. Prenat Diagn 2018, 38(4):243-245.

46. Hui L, Norton M: What is the real "price" of more prenatal screening and fewer diagnostic procedures? Costs and trade-offs in the genomic era. Prenat Diagn 2018, 38(4):246-249.

47. Garcia-Perez L, Linertova R, Alvarez-de-la-Rosa M, Bayon JC, Imaz-Iglesia I, Ferrer-Rodriguez J, Serrano-Aguilar P: Cost-effectiveness of cell-free DNA in maternal blood testing for prenatal detection of trisomy 21, 18 and 13: a systematic review. Eur J Health Econ 2018, 19(7):979-991.

48. Zhang H, Gao Y, Jiang F, Fu M, Yuan Y, Guo Y, Zhu Z, Lin M, Liu Q, Tian Z et al: Non-invasive prenatal testing for trisomies 21, 18 and 13: clinical experience from 146,958 pregnancies. Ultrasound Obstet Gynecol 2015, 45(5):530-538.

49. Cuckle H: Rethinking second-trimester Down-syndrome screening in the cell-free DNA era. Ultrasound in Obstetrics \& Gynecology 2019, 54(4):431-436.

50. Oepkes D, Bartha JL, Schmid M, Yaron Y: Benefits of contingent screening vs primary screening by cell-free DNA testing: think again. Ultrasound in Obstetrics \& Gynecology 2016, 47(5):542-545..

\section{Figures}


NIPT Primary Strategy 1

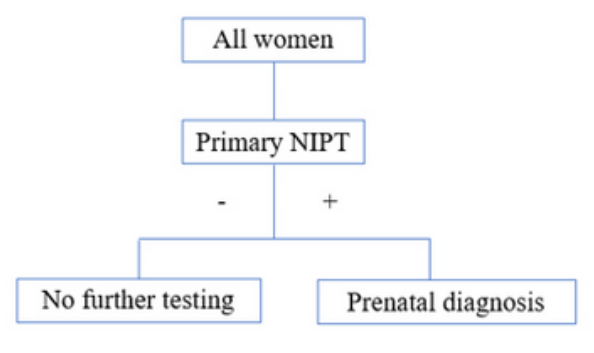

Contingent Strategy 2

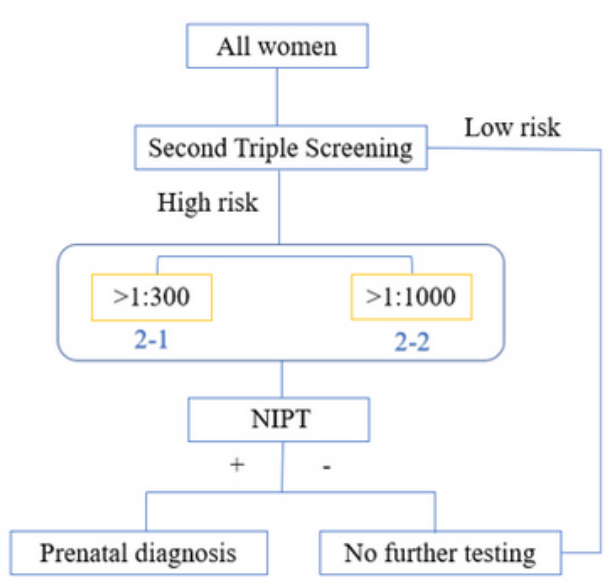

Age-stratified Strategy 3

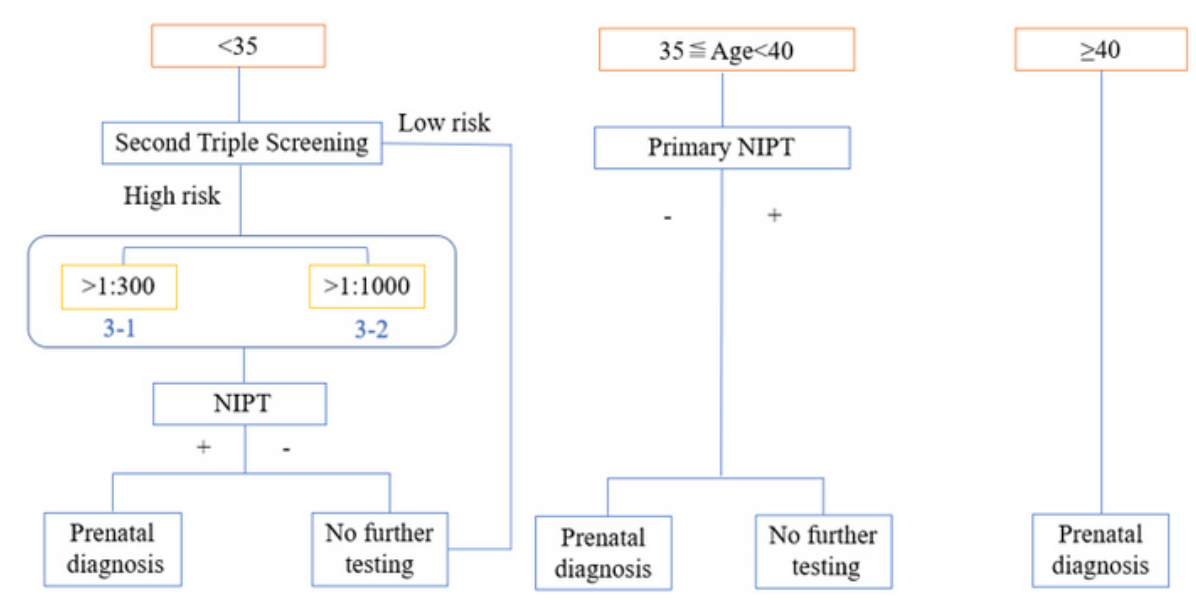

\section{Figure 1}

Conceptional framework of three strategies for implementing noninvasive prenatal testing (NIPT) 
- Medical Costs(Million US\$)

Costs of Medical Cases(Million US\$)

- Cost Effect Analysis(Thousand US\$ per)

(B)

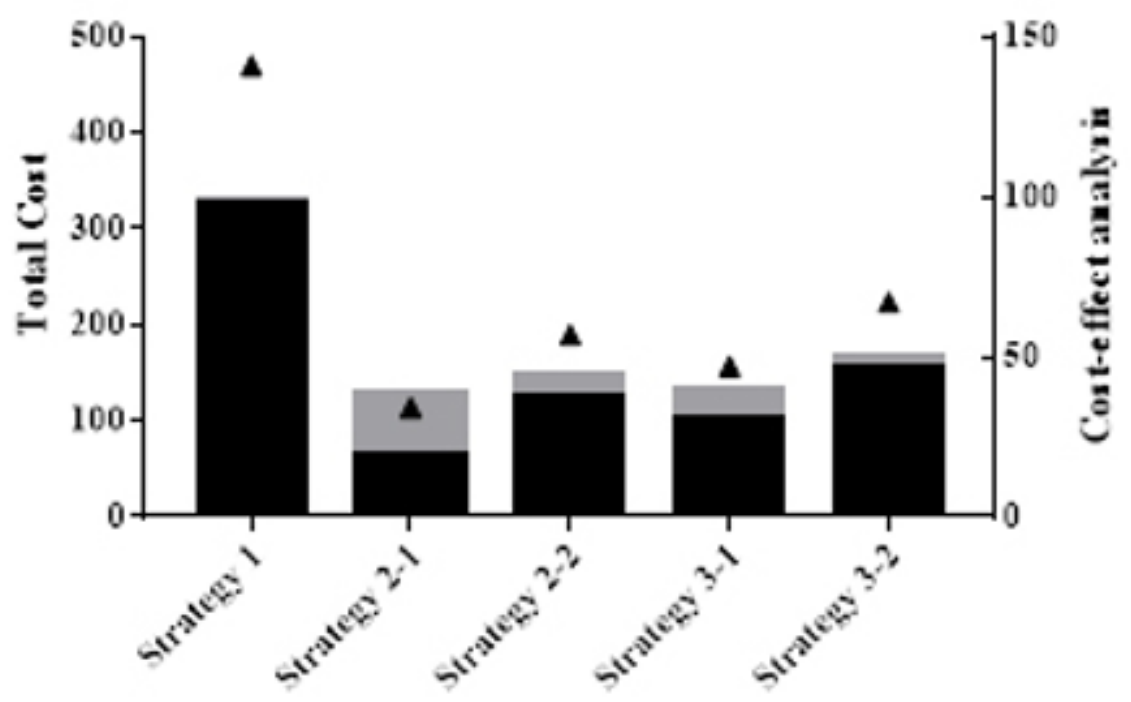

Figure 2

Total costs and cost-effect analysis of different strategies 
$\rightarrow$ Strategy 1

- Strategy 2-2

- Strategy 3-1

$\rightarrow$ Strategy 3-2

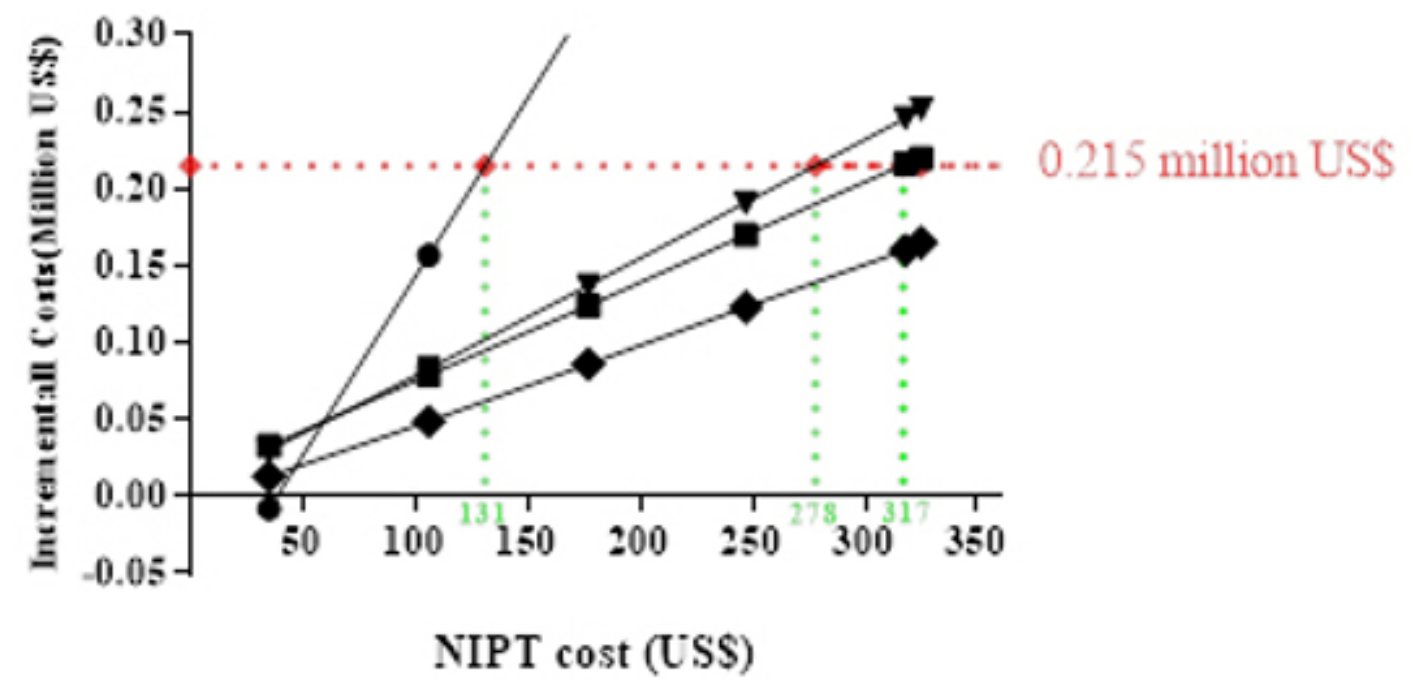

Figure 3

The incremental cost analysis for NIPT price setting strategy 2-1 as baseline. 